\title{
Frecuencia y características de uso de Internet por adolescentes españoles. Un estudio transversal
} Frequency and characteristics of Internet use by Spanish teenagers. A cross-sectional study

\author{
Dr. Ricardo E. Reolid-Martíneza, Dra. María Flores-Copete ${ }^{a}$, \\ Dra. Mónica López-García ${ }^{a}$ Dra. Pilar Alcantud-Lozano ${ }^{a}$, \\ Dra. M. Candelaria Ayuso-Raya y Dr. Francisco Escobar-Rabadán ${ }^{a}$
}

\section{RESUMEN}

Introducción: Internet ha transformado la comunicación entre las personas en el mundo actual, especialmente en el caso de los más jóvenes. Elobjetivo de este estudio es determinar la frecuencia de uso de Internet por adolescentes, así como las aplicaciones utilizadas.

Población y métodos: Se trata de un estudio transversal. En noviembre de 2013, los estudiantes de la escuela secundaria obligatoria de dos institutos de Albacete fueron invitados a responder un cuestionario autoadministrable, con preguntas de respuesta abierta y cerrada. Contestaron en las aulas, "on line" o con "lápiz y papel". Las respuestas fueron introducidas en una base de datosinformatizada, con el programa SPSS 17.0. El análisis estadístico ha incluido comparación de proporciones (chi cuadrado) y de medias/medianas ( $t$ de Student/pruebas no paramétricas).

Resultados: Participaron 967 estudiantes, con media de edad de 13,8 años (rango: 11-20); $53,5 \%$ de mujeres. La mayoría $(70,9 \%)$ vivían en la ciudad. La clase social era mayoritariamente media $(51,3 \%)$ y alta $(34,8 \%)$. La mayoría se conectaba a Internet a diario $(73,4 \%)$; solo $0,9 \%$ decía no conectarse nunca. Las aplicaciones más utilizadas eran WhatsApp $(77,1 \%)$, redes sociales $(70,1 \%)$ y relacionadas con música $(66,6 \%)$. Se ha encontrado una mayor frecuencia de utilización por las mujeres de redes sociales $(p=0,004)$, WhatsApp $(p<0,0001)$, Instagram $(\mathrm{p}<0,0001)$ y escuchar música $(\mathrm{p}=0,004)$. Los varones navegaban más ( $p<0,0001)$, utilizaban Skype $(p=0,001)$, jugaban $(p<0,0001)$ y veían películas o series $(p=0,035)$.

a. Centro de Salud Universitario Zona IV de Albacete. Albacete, España.

Correspondencia: Dr. Francisco EscobarRabadán: fjescobarr@ sescam.jccm.es

Conclusiones: Internet ocupa una gran parte del tiempo de los adolescentes, especialmente como medio de comunicación, y WhatsApp y las redes sociales son las aplicaciones que utilizan con más frecuencia.

Palabras clave: adolescente, Internet, medios de comunicación sociales, computadoras, teléfono celular.

http:/ /dx.doi.org/10.5546/aap.2016.6

Financiamiento:

Ninguno.

Conflicto de intereses:

Ninguno que declarar.

Recibido: 18-6-2015 Aceptado: 10-8-2015 mundo actual, lo que es especialmente relevante en el caso de los más jóvenes. La navegación por Internet, el uso de redes sociales virtuales, los videojuegos y el teléfono móvil han supuesto un cambio radical en las formas de comunicarse para la mayoría de ellos. ${ }^{1}$ Las aplicaciones de Internet ofrecen a los jóvenes nuevas oportunidades para la creatividad y el aprendizaje, junto con la posibilidad del intercambio y la comunicación horizontal. ${ }^{2}$ Las ventajas que nos brinda Internet son innegables, pero puede asociar un grado de dependencia que llegue a repercutir en la vida cotidiana. ${ }^{3}$

En la adolescencia, confluyen la búsqueda de la gratificación inmediata y la curiosidad por nuevas vivencias con una sensación de invulnerabilidad, por lo que los adolescentes están más expuestos a conductas de riesgo. Se ha descrito la "adicción a Internet", ${ }^{4}$ con el consiguiente desarrollo de literatura científica en relación con el impacto que pueda tener en la salud mental, 5,6 más allá de su posible utilización comercial, para la difusión y la venta de muy diversos productos (alcohol, tabaco, producciones musicales, juegos violentos, etc.). ${ }^{7}$ En el DSM $V$, se ha incorporado el llamado Internet Gaming Disorder. Junto con esta entidad clínica bien definida, se ha descrito también el uso excesivo de Internet, que no alcanza el rango de trastorno psicopatológico, aunque tiene consecuencias negativas en el ámbito académico o familiar. ${ }^{8}$

Se ha encontrado una asociación entre la adicción a Internet y diferentes 
trastornos psicopatológicos, ${ }^{9,10}$ y pueden presentar comorbilidad psiquiátrica entre un $13 \%$ y un $26 \%$ de los pacientes que la sufren, ${ }^{11}$ así como con ciertos rasgos de personalidad (introversión, depresión, agresividad, abuso de sustancias) que pueden predisponer a un aislamiento social, lo que los hace más susceptibles al uso excesivo de Internet. ${ }^{12}$

El objetivo principal de este estudio es determinar la frecuencia de uso de Internet por adolescentes, así como las aplicaciones utilizadas. Se han planteado, además, los siguientes objetivos secundarios:

- Conocer la frecuencia de uso de las redes sociales por adolescentes y cuáles son las más utilizadas;

- Determinar las estrategias de uso de Internet por parte de adolescentes que pueden implicar algún riesgo para ellos, sus familias o sus equipos informáticos;

- Conocer la opinión de los adolescentes sobre el control de sus padres en relación con el uso de Internet y determinar las posibles estrategias de evitación que utilizan.

\section{POBLACIÓN Y MÉTODOS}

Se trata de un estudio transversal. El tamaño muestral fue calculado para una proporción esperada de uso de Internet del $90 \%$, con una precisión de $\pm 2 \%$ y un nivel de confianza del $95 \%$ : 865. Se optó por una muestra de conveniencia: los alumnos de dos institutos con fácil acceso para los investigadores y cuyo número podía cubrir sobradamente el tamaño precisado. El proyecto fue aprobado por los órganos directivos de los centros de enseñanza en que fue realizado.

En noviembre de 2013, los estudiantes de la escuela secundaria obligatoria de dos institutos de Albacete fueron invitados a responder a un cuestionario autoadministrable (Anexo en versión electrónica) con preguntas de respuesta abierta y cerrada. Este fue específicamente diseñado a partir de la información encontrada en la revisión bibliográfica y de acuerdo con los objetivos del estudio. También recogía datos de edad, sexo, lugar de residencia y ocupación de los padres, sobre la base de la que se estimaba la clase social. ${ }^{13}$

- Clase I: directivos, profesionales.

- Clase II: gerentes/propietarios/profesionales de menor cualificación.

- Clase III: cuadros intermedios, administración, funcionarios.

- Clase IV a: trabajadores manuales cualificados.
- Clase IV b: trabajadores manuales semicualificados.

- Clase V: trabajadores no cualificados.

- Clase VI: otros (parados, pensionistas, amas de casa).

Se asignó a cada estudiante el código correspondiente a la más alta cualificación del padre y/o la madre (por ejemplo, si el padre era un trabajador manual cualificado y la madre era administrativa, el código sería 3). Para facilitar el manejo de la variable en menos categorías, se agruparon en los siguientes valores: 1 y 2: clase alta y media-alta. 3: clase media. 4-7: clase mediabaja y baja.

Se realizó una prueba piloto, en la que participaron 11 estudiantes voluntarios de otros institutos y que permitió corregir términos de difícil compresión o que pudieran inducir a confusión.

Los estudiantes que participaron en el estudio contestaron en aulas de su instituto, bien "on line" o con "lápiz y papel", con el consentimiento informado previo de los padres y profesores, y el asentimiento de los propios alumnos. Al menos, uno de los investigadores estuvo presente en la administración del cuestionario, con el objetivo de facilitar la contestación, así como para la aclaración de posibles dudas.

Las respuestas fueron codificadas e introducidas en una base de datos informatizada, con el programa SPSS 17.0. El análisis estadístico ha incluido comparación de proporciones (chi cuadrado) y de medias ( $t$ de Student) en el caso de variables continuas con distribución normal, y se recurrió a pruebas no paramétricas en caso contrario. Por medio de un análisis de regresión logística, se ha estudiado la relación entre la frecuencia de conexión a Internet y el uso de redes sociales con las diferentes variables sociodemográficas registradas.

\section{RESULTADOS}

Respondieron al cuestionario 967 estudiantes; no hubo rechazo a participar por parte de ninguno de ellos. En la Tabla 1, se describen sus características sociodemográficas. El rango de edades era de 11-20 años, y existía un ligero predominio de mujeres, sin diferencias significativas para estas dos variables entre ambos institutos. Tampoco existían diferencias significativas de edad entre ambos géneros.

La mayoría de los estudiantes se conectaba a diario (Tabla 2). Las opciones más extremas (conectarse ocasionalmente/varias horas al día) 
eran más frecuentes entre las mujeres $(\mathrm{p}=0,0002)$. Era más frecuente que los alumnos de clase social menos favorecida no se conectaran nunca o lo hicieran con frecuencia inferior a la semanal $(20,8 \%)$ frente a los de clase media y alta $(14,6 \%$ y $14,1 \%$, respectivamente; $p=0,03$ ). La frecuencia de conexión aumentaba en relación directa con la edad, con una mediana de 12 (rango intercuartílico -RI- 12-14) para los que no se conectaban nunca o lo hacían raramente y de 15 (RI: 14-15) para los que decían estar conectados de forma casi permanente $(p<0,0001)$. No existían diferencias significativas entre ambos institutos, ni por lugar de residencia, en cuanto a la frecuencia de conexión a Internet.

Las aplicaciones más utilizadas eran

TABla 1. Características sociodemográficas de los estudiantes que participaron en el estudio. La edad se presenta como media de los años cumplidos (desvío estándar) y el resto de variables como frecuencia relativa (\%)

\begin{tabular}{|c|c|c|c|}
\hline & Laboral $(n=559)$ & $N^{\circ} 7(n=408)$ & Total $(n=967)$ \\
\hline Edad & $\begin{array}{c}13,8(1,4) \\
{[\text { N. C.: 52] }}\end{array}$ & $\begin{array}{c}13,7(1,4) \\
{[\text { N. C.: 12] }}\end{array}$ & $\begin{array}{c}13,8(1,4) \\
{[\text { N. C.: 64] }}\end{array}$ \\
\hline \multicolumn{4}{|l|}{ Sexo } \\
\hline Mujeres & $279(54,5)$ & $210(52,2)$ & $489(53,5)$ \\
\hline Varones & $233(45,5)$ & $192(47,8)$ & $425(46,5)$ \\
\hline N. C. & 47 & 6 & 53 \\
\hline \multicolumn{4}{|l|}{ Clase social } \\
\hline Alta y media-alta & $144(29,4)$ & $158(41,7)^{*}$ & $302(34,8)$ \\
\hline Media & $72(14,7)$ & $80(21,1)$ & $152(17,5)$ \\
\hline Media-baja y baja & $273(55,8)$ & $141(37,2)^{*}$ & $414(47,7)$ \\
\hline N.C. & 70 & 29 & 99 \\
\hline \multicolumn{4}{|l|}{ Residencia } \\
\hline Urbana & $290(57,8)$ & $396(99,0)^{*}$ & $686(76,1)$ \\
\hline Rural & $212(52,2)$ & $4(1,0)^{*}$ & $216(23,9)$ \\
\hline N. C. & 57 & 8 & 65 \\
\hline
\end{tabular}

n: número de sujetos.

N. C.: no consta.

${ }^{*} \mathrm{p}<0,0001$.

TABla 2. Frecuencia de conexión a Internet y aplicaciones más utilizadas, en relación con el sexo de los estudiantes (\% en cada sexo)

\begin{tabular}{lccc}
\hline & Mujeres & Varones & Total \\
\hline Frecuencia de conexión & $5(1,0)$ & $4(1,0)$ & $9(1,0)$ \\
Nunca & $56(11,5)^{*}$ & $25(6,0)$ & $9(1,0)$ \\
Ocasionalmente & $19(3,9)$ & $31(7,5)$ & $50(5,5)$ \\
Semanalmente & $64(13,2)$ & $65(15,6)$ & $129(14,4)$ \\
Varias por semana & $82(42,8)$ & $106(25,5)$ & $188(20,8)$ \\
Diario, $<$ hora & $208(42,8)$ & $155(37,3)$ & $363(40,3)$ \\
Varias horas al día & $50(10,7)$ & $30(7,1)$ & $82(9,1)$ \\
Continuo & & & $239(26,2)$ \\
Aplicaciones & $115(23,6)$ & $124(29,2)$ & $419(46,0)$ \\
Correo electrónico & $181(37,2)$ & $238(56,1)^{* *}$ & $272(29,9)$ \\
Web & $141(29,0)$ & $131(30,9)$ & $106(11,6)$ \\
Chat & $50(10,3)$ & $56(13,2)$ & $211(23,2)$ \\
Contactos & $92(18,9)$ & $119(28,1)^{* * *}$ & $649(71,0)$ \\
Skype & $267(75,1)^{* * *}$ & $282(66,4)$ & $718(78,8)$ \\
Redes sociales & $309(84,0)^{* *}$ & $309(72,9)$ & $196(21,5)$ \\
WhatsApp & $150(30,7)^{* *}$ & $229(54,0) * * *$ & $313(34,3)$ \\
Instagram & $84(17,2)$ & $271(63,9)$ & $626(68,7)$ \\
Videojuegos & $155(72,9)^{* * *}$ & $144(34,0)^{* * * *}$ & $278(30,5)$ \\
Música & $134(27,5)$ & & \\
Películas/series & &
\end{tabular}

${ }^{*} \mathrm{p}=0,0002 ;{ }^{* *} \mathrm{p}<0,0001 ;{ }^{* * *} \mathrm{p}<0,01 ;{ }^{* * * *} \mathrm{p}<0,05$. 
WhatsApp $(77,1 \%$; IC 95\%: $74,4 \%-79,8 \%)$, redes sociales (70,1\%; IC 95\%: 67,2\%-73,1\%) y aquellas relacionadas con música $(66,6 \%$; IC95\%: $63,6 \%-69,6 \%)$. En la Figura 1, queda reflejada la frecuencia de utilización de las diferentes aplicaciones en cada instituto y, en la Figura 2, según el lugar de residencia. En la Tabla 2, se recoge la diferente utilización de las aplicaciones en función del género. Existía mayor probabilidad $(p<0,0001)$ de uso de ciertas aplicaciones a mayor edad: películas, música, Instagram, WhatsApp y redes sociales, así como de navegar por la Web $(p=0,014)$. En cuanto a la clase social, solo se encontraron diferencias significativas $(p=0,007)$ con relación al uso de redes sociales: $75,5 \%$ en clase media, frente a $68,9 \%$ en clase alta y $62,0 \%$ en clase baja.

Con relación a las redes sociales, Twitter era la más utilizada $(71,2 \%$; IC 95\%: 67,4-74,9) por los 579 usuarios que indicaban cuáles eran sus preferidas, seguida por Tuenti $(58,7 \%$; IC $95 \%$ : 54,6-62,8) y Facebook (20,9\%; IC 95\%: 17,5-24,3).

FIGURA 1. Porcentaje de utilización de las diferentes aplicaciones en cada instituto

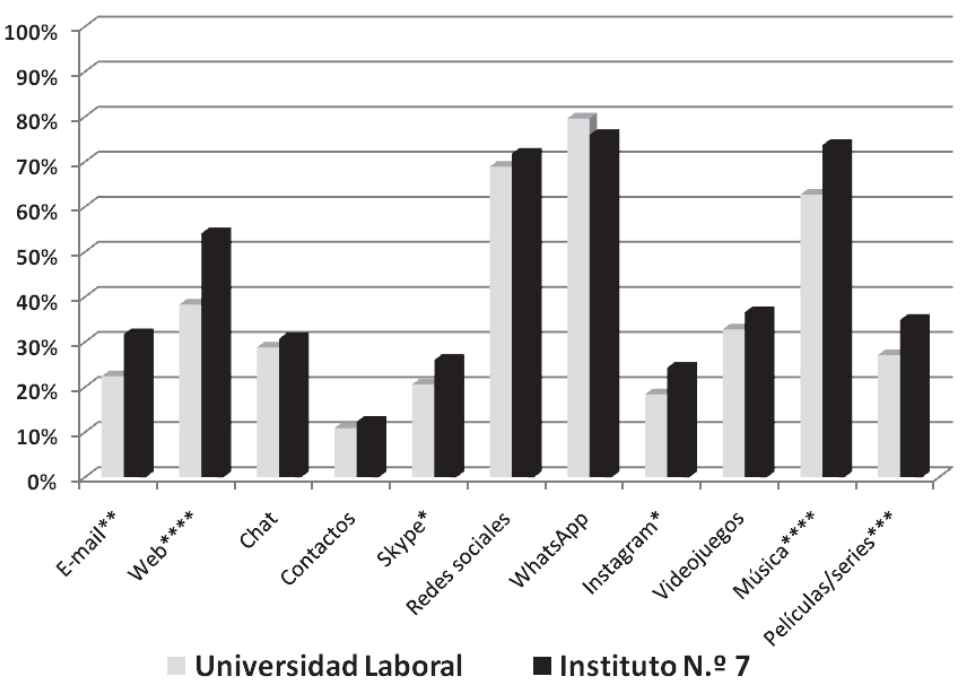

${ }^{*} \mathrm{p}<0,05 ;{ }^{* *} \mathrm{p}<0,01 ;{ }^{* * *} \mathrm{p}<0,001 ; * * * * \mathrm{p}<0,0001$.

Figura 2. Porcentaje de utilización de las diferentes aplicaciones en el medio rural y urbano

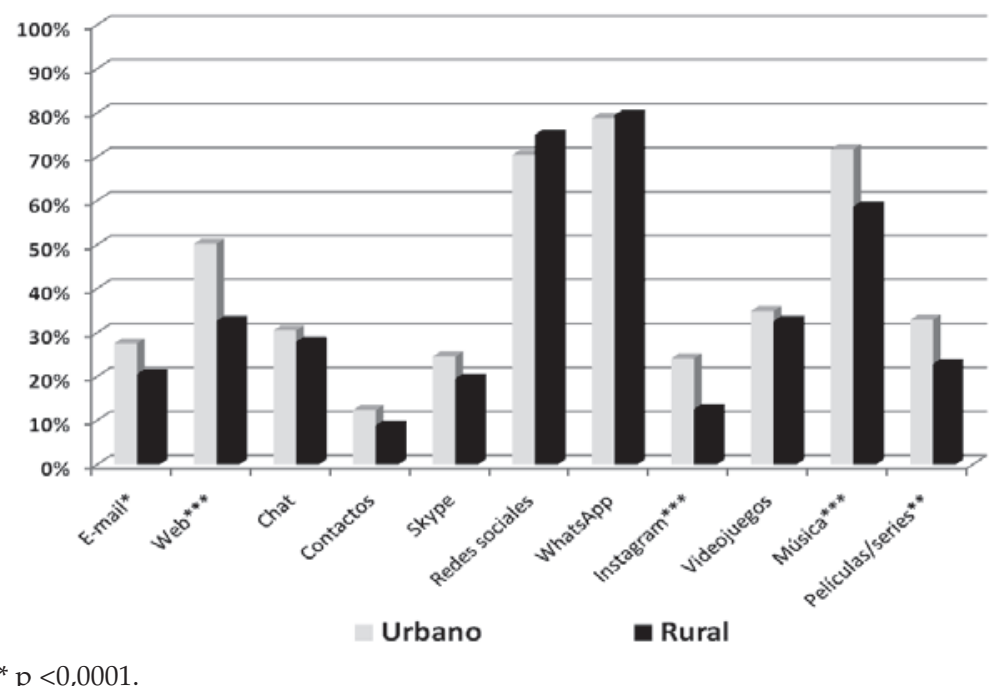

${ }^{*} \mathrm{p}<0,05 ;{ }^{* *} \mathrm{p}<0,01 ;{ }^{* * *} \mathrm{p}<0,0001$. 
Algunos utilizaban otras redes, ya sea a través de Google (Hangouts) o Yahoo (Messenger) u otras, como Ask, Chatroulette, Heello, Tumblr, Habbo, Wattpad, Metroflog, aunque de forma más minoritaria. Era habitual el uso combinado de más de una red, en el que se destacó el de Twitter y Tuenti por el 34,3\%.

Twitter era más utilizado por las mujeres $(p=0,007)$ y Facebook por los varones $(p=0,024)$, mientras que para Tuenti no había diferencias por sexo. En cuanto a la edad, era significativamente más probable $(\mathrm{p}<0,0001)$ que los usuarios de Tuenti fueran más jóvenes (mediana y RI: 14 y $13-15$ vs. 15 y 14-15) y los de Twitter mayores que los que no los usaban (mediana y RI: 14 y 13-15 vs. 13 y 12-15). No existían diferencias en el uso de las redes sociales según el lugar de residencia o la clase social. Tampoco existían diferencias significativas entre los dos institutos en cuanto al uso de Twitter y Tuenti, y solo el uso de Facebook era algo más frecuente en los alumnos de la Universidad Laboral: $24,0 \%$ vs. $16,5 \%$ ( $p=0,028)$.

En la Tabla 3, se presentan los resultados de los análisis de regresión logística, que demuestran que la conexión diaria a Internet se asocia de forma independiente con la edad y la clase social, y que el uso de redes sociales se asocia, además, con el género, ya que las mujeres tienen mayor probabilidad de usarlas.

En la Figura 3, se muestra el porcentaje de seguimiento de comportamientos de riesgo y sus diferencias por género. Solo un 5,9\% rechazaba la existencia de riesgos en Internet. Un 67,3\% consideraba que existía riesgo al chatear y se destacaba la preocupación por contactos con desconocidos/invasión de intimidad/acoso del $95,7 \%$. El $84,5 \%$ pensaba que no era seguro compartir contraseñas. Un $46,6 \%$ decía haber encontrado en redes sociales fotos suyas no deseadas, aunque el 44,9\% subía fotos con otras personas. El 58,8\% solo aceptaba "solicitudes de amistad" de quienes conocían personalmente. Un 12,2\% decía haberse sentido alguna vez insultado en redes sociales, y 8,3\%, implicado en cyberbullying, ya fuera como víctima, acosador o ambos.

Un 75,6\% (IC 95\%: 72,8-78,4) creía que sus padres confiaban en ellos acerca del uso de Internet, y un 11,8\% (IC 95\%: 9,7-13,9), que solo sabían parte de lo que hacían. Al 65,5\% les preocupaba que sus padres vieran qué hacían en Internet, y un $36,3 \%$ no aceptaba el posible control de estos (en las respuestas abiertas, hacían frecuente referencia a "su intimidad"). Sin embargo, el 59,7\% estaba de acuerdo, compartía claves o tenía agregados a sus padres en redes sociales.

Solo un 30,5\% (IC 95\%: 27,5-33,5) no utilizaba estrategias de ocultación de su actividad en Internet. La más utilizada era borrar el historial de navegación (36,3\%), seguida por conectarse a Internet solo desde el móvil o tableta $(28,3 \%)$, minimizar navegadores y ventanas si se acercaba un adulto $(27,8 \%)$ y esconder o borrar chats $(25,6 \%)$.

Solamente un 6,9\% (IC 95\%: 5,3-8,6) decía no tener móvil (algunos, incluso, indicaban no estar interesados en ellos). Sin embargo, para el

TABla 3. Análisis de regresión logística binaria para las variables dependientes: frecuencia de conexión (diaria vs. menos frecuente), uso de redes sociales (sí vs. no), tanto de forma general como para el uso específico de Twitter, Tuenti y Faceboook

\begin{tabular}{|c|c|c|c|}
\hline Variable dependiente & Variables independientes & OR & IC $95 \%$ \\
\hline $\begin{array}{l}\text { Frecuencia de conexión } \\
\text { (diaria vs. inferior) }\end{array}$ & $\begin{array}{l}\text { Edad } \\
\text { Clase social (vs. clase baja) } \\
\text { Alta } \\
\text { Media }\end{array}$ & $\begin{array}{l}2,1 \\
1,9\end{array}$ & $\begin{array}{l}1,6-2,2 \\
1,2-3,8 \\
1,1-3,3\end{array}$ \\
\hline $\begin{array}{l}\text { Uso de redes sociales } \\
\text { (sí vs. no) }\end{array}$ & $\begin{array}{l}\text { Edad } \\
\text { Clase social (vs. clase baja) } \\
\quad \text { Alta } \\
\quad \text { Media } \\
\text { Sexo (chicas vs. chicos) }\end{array}$ & $\begin{array}{l}1,9 \\
2,4 \\
1,8\end{array}$ & $\begin{array}{l}1,4-1,8 \\
1,1-3,0 \\
1,5-3,8 \\
1,3-2,5\end{array}$ \\
\hline $\begin{array}{l}\text { Uso de Twitter } \\
\text { (sí vs. no) }\end{array}$ & $\begin{array}{l}\text { Edad } \\
\text { Sexo (chicas vs. chicos) }\end{array}$ & $\begin{array}{l}1,6 \\
2,0\end{array}$ & $\begin{array}{l}1,4-1,9 \\
1,3-2,9\end{array}$ \\
\hline $\begin{array}{l}\text { Uso de Tuenti } \\
\text { (sí vs. no) }\end{array}$ & Edad & 0,6 & $0,6-0,7$ \\
\hline $\begin{array}{l}\text { Uso de Facebook } \\
\text { (sí vs. no) }\end{array}$ & $\begin{array}{l}\text { Sexo (chicas vs. chicos) } \\
\left.\text { Instituto (Laboral vs. } N^{\circ} 7\right)\end{array}$ & $\begin{array}{l}0,6 \\
1,7\end{array}$ & $\begin{array}{l}0,4-0,9 \\
1,1-2,6\end{array}$ \\
\hline
\end{tabular}


$81,5 \%$ de los encuestados (IC 95\%: 78,9-84,0) era el medio habitual de conexión a Internet. Pero los usuarios de móvil le atribuían muchas otras utilidades (en alguna de las respuestas "abiertas", se indicaba que lo usaban "para todo"). En cuanto a las funciones de comunicación, destacaban, por orden de frecuencia, WhatsApp $(88,4 \%)$, llamadas $(81,8 \%)$, SMS $(45,3 \%)$ y correo electrónico $(27,8 \%)$. Otro uso destacado era en relación con la música $(83,4 \%)$, juegos $(52,2 \%)$ o su uso como agenda $(32,7 \%)$ y un largo etcétera, que incluiría el uso como cámara, despertador o linterna.

\section{DISCUSIÓN}

Los resultados de este estudio ponen de manifiesto que Internet ocupa una gran parte del tiempo de los adolescentes, en especial como medio de comunicación, y que WhatsApp y las redes sociales, sobre todo Twitter, son las aplicaciones que utilizan con más frecuencia. El móvil es utilizado por la inmensa mayoría de los adolescentes y constituye una herramienta esencial en sus actividades diarias. El adolescente se expresa con el móvil y a través de él; es una señal de identidad para ellos que les ha servido para alcanzar su independencia comunicativa. ${ }^{1}$

Este trabajo aporta una actualización de las tendencias de uso en un ámbito tan cambiante como el de las nuevas tecnologías. Sin embargo, habría que considerar como posible limitación las potenciales diferencias geográficas o culturales, que podrían determinar los patrones de uso, aún a pesar de la globalización que impera en el mundo actual.

En España, según la Encuesta Nacional de Salud de 2014, ${ }^{14}$ el uso de Internet, y sobre todo de la computadora, es una práctica mayoritaria ya en edades anteriores a los 10 años. El 74,4\% de los hogares dispone de conexión a Internet, el uso de la computadora entre los menores alcanza el 93,8\%, y el 92,0\% utiliza Internet. La disposición de teléfono móvil se incrementa a partir de los 10 años hasta alcanzar el 90,3\% a los 15 .

Los datos de un estudio realizado en Madrid constatan la asociación entre el alto uso de Internet y del teléfono móvil, lo que refuerza la idea de una alteración global del comportamiento ante estas nuevas TIC. Además, se ha relacionado el consumo de tóxicos, especialmente alcohol o cannabis, con un aumento del uso de Internet. ${ }^{7}$ Otro estudio en diferentes colegios e institutos de Burgos, que incluyó 2063 entrevistas a jóvenes de entre 10 y 18 años, mostró que el uso de las TIC es mayoritario e, incluso, puede considerarse como masivo: $10 \%$ de los adolescentes reconocía abusar de las TIC. ${ }^{15}$

En Europa, Durkee et al. ${ }^{16}$ han descrito prevalencias de adicción a Internet que oscilarían entre un $2 \%$ en Noruega y un 18,3\% en Inglaterra. Asimismo, han encontrado un mayor riesgo entre personas pertenecientes a áreas desfavorecidas y minorías culturales, mientras que la religión

FiguRA 3. Porcentaje de realización de "actividades de riesgo" (para tratar de contrarrestar el impacto negativo de algunas de las repuestas, se buscó el enmascaramiento con respuestas neutras del tipo "buscar información en relación con alguna asignatura") en internet, en mujeres y varones

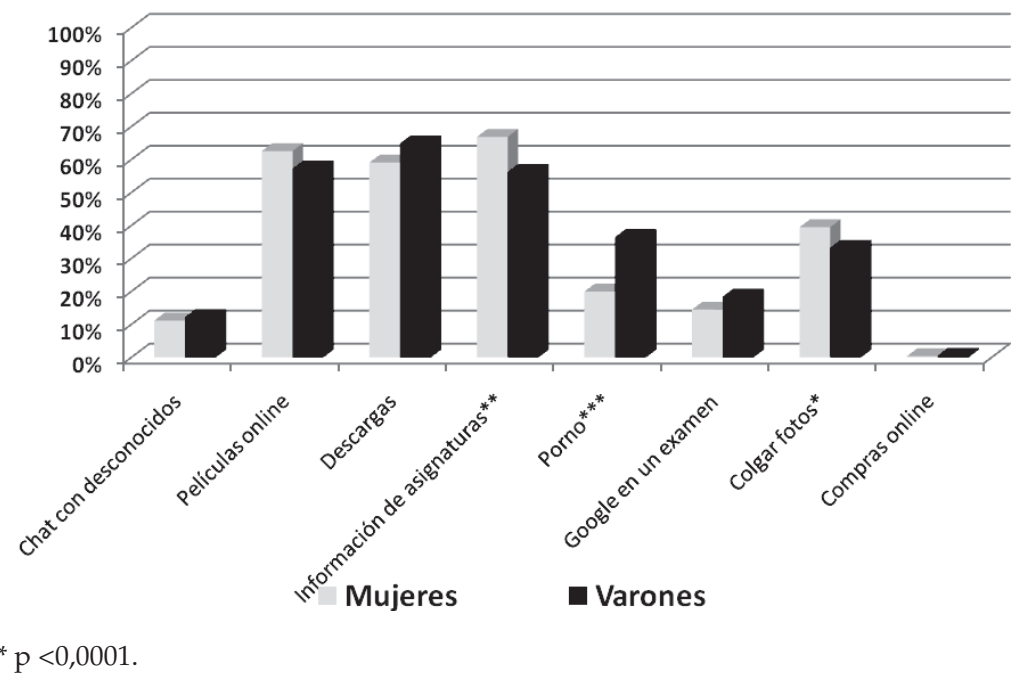

${ }^{*} \mathrm{p}<0,05 ;{ }^{* *} \mathrm{p}<0,01 ;{ }^{* * *} \mathrm{p}<0,0001$. 
sería un factor protector. Con relación al género, los adolescentes masculinos presentarían más comportamientos patológicos en relación con el uso de Internet. En cualquier caso, los jóvenes con mayor riesgo de abusar de Internet, que llegan a desarrollar conductas adictivas, serían aquellos con falta de apoyo psicológico y emocional, así como aquellos con baja autoestima o problemas adaptativos al entorno. ${ }^{7}$ Además, Tsitsika et al. ${ }^{17}$ comprobaron que los adolescentes de padres con un alto nivel cultural tenían una menor probabilidad en el uso inadecuado de Internet.

Nuestros resultados subrayan distintas preferencias en cuanto a redes sociales asociadas a edad, sexo y clase social. Siguiendo a PujazonZazik y Park, ${ }^{18}$ podemos diferenciar tres etapas en la adolescencia, cada una de ellas asociada a distintas necesidades que se pueden extrapolar al ámbito internauta. La adolescencia temprana (10-13 años) se caracteriza por la adquisición de un comportamiento independiente. La media (14-17 años) comprende los primeros deseos por atraer al sexo opuesto y el interés por él (esta es la fase con más probabilidad de establecer contacto vía chat con personas desconocidas y con más riesgo de acoso sexual). La tardía (1721 años) presenta una mayor identidad personal e independencia de las opiniones ajenas, así como mayor interés en las relaciones interpersonales, sin importar tanto lo que opine el grupo, con un uso más responsable.

Una de las preocupaciones que ha despertado el uso de las redes sociales por parte de los adolescentes es cómo puede afectar la imagen corporal. Los adolescentes con insatisfacción corporal e interiorización de un ideal físico de cuerpo delgado podrían usar más las aplicaciones fotográficas, lo que exacerbaría problemas de imagen corporal preexistentes. ${ }^{19}$ Otro de los riesgos que se ha atribuido al uso de las redes sociales es el de una mayor promiscuidad sexual. En este sentido, se ha asociado el uso de una cuenta de Facebook con tener múltiples parejas en el último año, así como con que estas sean de edades dispares. ${ }^{20}$

La inmensa mayoría de los adolescentes que participaron en nuestro estudio reconocen la existencia de peligros en el uso de Internet, especialmente en relación con un posible acoso. Sin embargo, esto no evita el seguimiento de patrones de riesgo. La mayoría cree que sus padres tienen confianza en cuanto a su actividad en Internet. Aún así, utilizan con gran frecuencia estrategias de ocultamiento.
El término "cyberbullying" está siendo revisado. Para que existiera este tipo de hostigamiento, se deberían cumplir criterios, tales como la finalidad de hacer daño, utilizar un patrón de comportamiento repetitivo, ser realizado dentro de un marco en el que se encuentran involucrados tecnología, anonimato y/o vida social. Esto diferencia el "cyberbullying" de otras formas de acoso, bien sobre un grupo concreto de personas (como en la pedofilia) o indiscriminado (como en el envío masivo de virus). De ahí que estén surgiendo nuevos términos como "cyber-teasing" (ciberburlas) y "cyber-arguing" (ciberdiscusión). ${ }^{21}$

En cuanto a la supervisión paterna, esta se considera un factor protector clave. ${ }^{22} \mathrm{Sin}$ embargo, como se demostró en el estudio Jóvenes y Tecnología de la Información y la Comunicación (Joves i Tecnologies de la Informació i la Comunicació; JOITIC, por sus siglas en catalán), ${ }^{5}$ el control parenteral es bajo y disminuye con la edad. Esta falta de supervisión por parte de los padres y la carencia de cierta disciplina, junto con pobres relaciones intrafamiliares, se han señalado entre las causas del desarrollo de un problema adictivo en relación con Internet. ${ }^{7}$ Como señalan Şenormanc1, et al. ${ }^{8}$ las familias que resuelven sus problemas juntos, tienen lazos emocionales, comparten roles, se cuidan sin limitar la libertad del otro, ejercen un control moderado sobre los comportamientos y tienen una comunicación abierta, cómoda y directa podrán enfrentar mejor estos nuevos desafíos.

Como conclusión de nuestro estudio, queremos resaltar que Internet ocupa una gran parte del tiempo de los adolescentes, especialmente como medio de comunicación, con WhatsApp y las redes sociales como aplicaciones más utilizadas, y llamar la atención sobre el seguimiento de patrones de riesgo a pesar de conocer los peligros potenciales.

\section{REFERENCIAS}

1. Bercedo Sanz A, Redondo Figuero C, Pelayo Alonso R, Gómez Del Río Z, et al. Consumo de los medios de comunicación en la adolescencia. An Pediatr (Barc) 2005;63(6):516-25.

2. MiguelGonzález I, Echevarría BrozC, Ferrero FernándezE, Suárez Gil P. Uso de Internet por parte de los adolescentes deGijón (Asturias) como fuente deinformación sobre salud. Aten Primaria 2011;43(6):281-6.

3. Cho H, Kwon M, Choi JH, Lee SK, et al. Development of the Internet addiction scale based on the Internet Gaming Disorder criteria suggested in DSM-5. Addict Behav 2014;39(9):1361-6.

4. Weinstein A, Lejoyeux M. Internet addiction or excessive Internet use. Am J Drug Alcohol Abuse 2010;36(5):277-83.

5. Muñoz-Miralles R, Ortega-GonzálezR, Batalla-MartínezC, 
López-Morón MR, et al. Acceso y uso denuevas tecnologías entre los jóvenes de educación secundaria, implicaciones en salud. Estudio JOITIC. Aten Primaria 2014;46(2):77-88.

6. Lam-Figueroa N, Contreras-Pulache H, Mori-Quispe E, Nizama-Valladolid M, et al. Adicción a internet: desarrollo y validación de un instrumento en escolares adolescentes de Lima, Perú. Rev Peru Med Exp Salud Publica 2011;28(3):462-9.

7. Sánchez-Martínez M, Otero Puime A. Usos de internet y factores asociados en adolescentes de la Comunidad de Madrid. Aten Primaria 2010;42(2):79-85.

8. Şenormanc1 Ö, Şenormanc1 G, Güçlü O, Konkan R. Attachment and family functioning in patients with Internet addiction. Gen Hosp Psychiatry 2014;36(2):203-7.

9. $\mathrm{Ko} \mathrm{CH}$, Yen JY, Yen CF, Chen CS, et al. The association between Internet addiction and psychiatric disorder: a review of the literature. Eur Psychiatry 2012;27(1):1-8.

10. Carli V, Durkee T, Wasserman D, Hadlaczky G, et al. The association between pathological internet use and comorbid psychopathology: a systematic review. Psychopathology 2013;46(1):1-13.

11. HoRC, Zhang MW, Tsang TY, Toh AH, etal. The association between internet addiction and psychiatric co-morbidity: a meta-analysis. BMC Psychiatry 2014;14:183.

12. Evren C, Dalbudak E, Evren B, Demirci AC. High risk of Internet addiction and its relationship with lifetime substance use, psychological and behavioral problems among $10^{\text {th }}$ grade adolescents. Psychiatr Danub 2014;26(4):330-9.

13. Domingo Salvany A, Marcos Alonso J. Propuesta de un indicador de la clase social basado en la ocupación. Gac Sanit 1989;3(10):320-6.

14. España. MinisteriodeSanidad,ServiciosSocialese Igualdad.
Encuesta Nacional deSalud de España 2011/12. [Consulta: 27 de enero de 2015]. Disponible en: http:/ /www.msssi. gob.es/estadEstudios/estadisticas/encuestaNacional/.

15. Lara Ortega F, Fuentes Gómez M, dela Fuente Anuncibay R, Pérez del Río F, etal. Uso y abuso de las nuevas tecnologías. Trastor Adict 2010;12(1):2-4.

16. Durkee T, Kaess M, Carli V, Parzer P, et al. Prevalence of pathological internet use among adolescents in Europe: demographic and social factors. Addiction 2012;107(12):2210-22.

17. Tsitsika A, Janikian M, Schoenmakers TM, Tzavela EC, et al. Internet addictive behaviour in adolescence: a crosssectional study in seven European countries. Cyberpsychol Behav Soc Netw 2014;17(8):528-35.

18. Pujazon-Zazik M, Park MJ. To tweet, or not to tweet: gender differences and potential positive and negative health outcomes of adolescents' social internet use. Am J Mens Health 2010;4(1):77-85.

19. Meier EP, Gray J. Facebook photo activity associated with body image disturbance in adolescent girls. Cyberpsychol Behav Soc Netw 2014;17(4):199-206.

20. Kaufman ZA, Braunschweig EN, Feeney J, Dringus S, et al. Sexual risk behavior, alcohol use, and social media use among secondary school students in informal settlements in Cape Town and Port Elizabeth, South Africa. AIDS Behav 2014;18(9):1661-74.

21. Vandebosch H, Van Cleemput K. Defining cyberbullying: a qualitative research into the perceptions of youngsters. Cyberpsychol Behav 2008;11(4):499-503.

22. Strasburger VC, Jordan AB, Donnerstein E. Health effects of media on children and adolescents. Pediatrics 2010;125(4):756-67. 


\section{ANEXO}

Este cuestionario forma parte de un estudio sobre el uso de las tecnologías digitales por parte de los adolescentes.

La participación es voluntaria.

El cuestionario es totalmente anónimo, y tus respuestas nunca serán asociadas con tu identidad. Contestarlo puede llevarte unos pocos minutos.

Por favor, marca la respuesta que esté más próxima a tu caso para cada una de las preguntas.

1. ¿Con qué frecuencia te conectas a Internet?
a) Nunca.
b) Ocasionalmente (de vez en cuando, puntualmente).
c) Menos de una vez a la semana, pero todos los meses.
d) Al menos, una vez a la semana.
e) Varios días a la semana.
f) A diario, no más de una hora.
g) Varias horas, todos los días.
h) No paso más de una hora sin conectarme.
i) Otra (especifica):

2. Si la respuesta ha sido NUNCA, ¿cuáles serían las razones? (Si has elegido otra opción, pasa a la pregunta siguiente).
a) No me interesa.
b) No lo necesito.
c) No tengo computadora.
d) No tengo acceso a Internet.
e) Es demasiado caro.
f) Miedo a virus, hackers...
g) Miedo a perder privacidad.
h) Otra (especifica):

3. Si utilizas Internet, ¿qué tipo de aplicaciones son las que usas? (Puedes seleccionar todas las respuestas que desees).
a) Correo electrónico.
b) Navegar por la Web.
c) Chats.
d) Contactos.
e) Skype.
f) Redes sociales (especifica cuál o cuáles):
g) WhatsApp.
h) Instagram.
i) Videojuegos.
j) Música.
k) Películas.
1) Otra: 
4. ¿Te has conectado alguna vez a Internet para lo siguiente? (varias respuestas posibles):
a) Conversaciones con desconocidos (por ejemplo, en un chat).
b) Ver películas on line.
c) Descargas.
d) Buscar información para temas de tus asignaturas.
e) Ver páginas porno.
f) Consultar en Google en un examen.
g) "Colgar" fotos.
h) Otras (especifica):

5. ¿Qué crees que saben tus padres sobre tu actividad en Internet?
a) Mis padres confían en mí (acerca del uso de Internet).
b) Mis padres solo saben parte, pero no todo lo que hago en Internet.
c) Mis padres no tienen tiempo de vigilar qué hago en Internet.
d) A mis padres no les preocupa lo que haga en Internet.
e) Otra (especifica):

6. ¿Te preocupa que tus padres vean qué haces en Internet?
a) No.
b) Sí.
c) No sé.

7. ¿Qué opinas sobre el posible control de los padres en el acceso a Internet?
a) No estoy de acuerdo.
b) Comparto con mis padres mis claves de acceso.
c) Tengo agregados a mis padres (o alguno de ellos) en mi red (o redes) social (sociales).
d) Otra (especifica):

8. ¿Crees que hay algún peligro en navegar por Internet? (Señala todas las respuestas que desees).
a) No.
b) Riesgos al hablar con desconocidos en un chat.
c) Riesgos al hacer compras con tarjeta electrónica.
d) Riesgos relacionados con que se conozca información personal.
e) Riesgo de entrada de virus.
f) Otro (especifica):

9. ¿Dónde tienes acceso a Internet? (Señala todas las respuestas correctas).
a) En zonas wifi.
b) En mi casa.
c) Continuamente, en el móvil (o tableta).
d) Otra (especifica):

10. ¿Cuál es el medio habitual por el que te conectas a Internet? (Señala todas las respuestas correctas).
a) Móvil.
b) Computadora familiar.
c) Portátil/computadora propia.
d) Otra (especifica): 
11. ¿Tienes en tu dormitorio lo siguiente? (señala todas las respuestas correctas):
a) Televisión.
b) Computadora, pero sin acceso a Internet.
c) Computadora (o smartphone o tableta) con acceso a Internet.
d) Consola de videojuegos.
e) No tengo ninguno de ellos.

12. ¿Crees que ver películas en sitios web, como YouTube o Metacafe, resulta más segura que descargar películas (por la posibilidad de que contengan virus)?
a) Sí.
b) No.
c) No sé.

13. ¿Piensas que los sitios de transmisión de bits o los programas de uso compartido de archivos son legales?
a) Sí.
b) No.
c) No sé.

14. ¿Crees que estas webs de transmisión de bits o los programas de uso compartido de archivos permiten la entrada en el equipo de archivos con virus?
a) Sí.
b) No.
c) No sé.

15. ¿Piensas que hay algún riesgo en chatear por Internet?
a) Sí (especifica):
b) No.
c) No sé.

16. ¿Piensas que es seguro compartir contraseñas (por ejemplo, de juegos online) con amigos?
a) Sí.
b) No.
c) No sé.

17. ¿Qué piensas sobre el hecho de bajarse trabajos de la web para entregarlos en clase como hechos por ti? (Varias respuestas posibles).
a) Eso no debe considerarse robar, pues el autor original vendió su trabajo al sitio web en cuestión.
b) Los profesores no saben utilizar Internet a ese nivel, de modo que nunca te descubrirán.
c) Si no tengo otra opción (por ejemplo, por falta de tiempo), vale la pena arriesgarse.
d) No estoy de acuerdo con ninguna de las anteriores.

18. ¿Sueles colgar fotos en las redes sociales?
a) Subo la mayoría de las fotos que tengo.
b) Subo solo algunas fotos, independientemente de quién salga en ellas.
c) Solo subo fotos en las que aparezco yo. Si sale más gente, primero pido su permiso.
d) Nunca subo fotos mías o de mis amigos.

19. ¿Tus amigos han colgado alguna foto tuya en las redes sociales?
a) Muchas veces.
b) Alguna vez.
c) Nunca. 
20. Cuando un amigo cuelga una foto tuya en una red social, ¿te pide primero permiso?
a) Sí, siempre.
b) Depende del amigo.
c) No, nunca me han pedido permiso.
d) Mis amigos no suben fotos mías a Internet.

21. ¿Alguna vez has visto una foto tuya que hubieras preferido que no hubieran colgado?
a) Muchas veces.
b) Alguna vez.
c) Nunca.

22. ¿Aceptas todas las solicitudes de amistad que recibes?
a) Sí, siempre, aunque no sepa quién es.
b) Acepto a mis amigos y también a amigos de mis amigos, aunque no los conozca en persona.
c) Solo acepto a amigos a los que ya conozco en persona.
d) En alguna ocasión, he aceptado la solicitud de alguien a quien no conocía en persona.

23. ¿Alguna vez te has sentido insultado o humillado en las redes sociales?
a) Sí, muchas veces.
b) Sí, alguna vez.
c) No, casi nunca.
d) No, nunca.

24. ¿Te has visto implicado en alguna situación que pudiera considerarse de acoso a través de Internet (cyberbullying)?
a) Sí, he sido víctima de cyberbullying.
b) Sí, he presionado a alguien a través de Internet.
c) Sí, a veces he podido presionar a alguien y otras haber sido presionado.
d) No.
e) No lo sé.

25. ¿Qué información proporcionas en tu perfil de redes sociales? (Varias respuestas posibles).
a) Sexo.
b) Fecha de nacimiento.
c) Origen.
d) Ciudad de residencia actual.
e) Miembros de la familia.
f) Situación sentimental.
g) Intereses (hombres/mujeres).
h) En busca de (amistad, encuentro, una relación...).
i) Opiniones (políticas, religiosas...).
j) Actividades en las que estás interesado (música, libros, televisión...).
k) Número de móvil.
1) Dirección.
m) Otros (especifica):

26. ¿Alguna vez ha sufrido daños tu computadora por infectarse con virus?
a) Nunca.
b) Sí (indica el número de veces que recuerdas):
c) No lo sé. 
27. ¿Utilizas alguna de estas estrategias? (varias opciones de respuesta son posibles):
a) Borrar el historial de navegación de Internet.
b) Minimizar navegadores y ventanas si se acerca un adulto.
c) Esconder o borrar chats.
d) Mentir sobre tus actividades online.
e) Utilizar una computadora a la que no tengan acceso tus padres.
f) Conectarte a Internet solo desde el móvil (o tableta).
g) Utilizar ajustes de privacidad para que tus contenidos solo sean visibles para quien tú quieras.
h) Usar modos privados de navegación para no dejar rastro.
i) Tener cuentas de correo desconocidas por tus padres.
j) Tener un perfil (o perfiles) falso en redes sociales.
k) Otra estrategia similar (especifica):
l) No utilizo ninguna de estas estrategias.

28. ¿Cuántas horas al día dedicas a las siguientes actividades de lunes a viernes?
a) TV:
b) Internet:
c) Móvil (incluida Internet):
d) Videoconsola:

29. ¿Cuántas horas al día dedicas a las siguientes actividades los sábados, domingos o días festivos?
a) TV:.
b) Internet:
c) Móvil (incluida Internet):
d) Videoconsola:

30. ¿Para qué utilizas el móvil?
a) Llamadas.
b) WhatsApp.
c) Listín telefónico.
d) Despertador.
e) Agenda.
f) Mensajes.
g) Correo electrónico.
h) Juegos.
i) Música.
j) Calculadora.
k) Otra (especifica):
l) No tengo móvil.

31. ¿Qué tipos de videojuegos utilizas? (Varias respuestas posibles).
a) Disparos-luchas.
b) Deportes.
c) Conducción.
d) Aventuras.
e) Otros (especifica):
f) No utilizo videojuegos. 
32. ¿Utilizas Internet para algo relacionado con la medicina? (Varias respuestas posibles).
a) Buscar información sobre enfermedades.
b) Buscar información sobre síntomas que puedas haber tenido.
c) Preguntar a otras personas (por ejemplo, en un chat).
d) Solicitar cita para el médico.
e) Consultar con tu médico.
f) Comprar medicamentos.
g) Buscar información para trabajos de alguna asignatura.
h) Otra (especifica):

33. ¿Qué opinas de la información que se puede encontrar en Internet sobre medicina?
a) Me parece muy fiable.
b) Si lo dice en Internet, es porque es verdad.
c) En Internet, hay información muy variada y no toda es fiable.
d) No me fío de nada que digan en Internet.
e) Otra (especifica):

34. Si has buscado alguna vez información sobre temas de medicina en Internet, ¿qué temas recuerdas?

\section{Por favor, indica los datos que se solicitan a continuación:}

- Edad (años cumplidos):

- Sexo: femenino/masculino.

- Curso:

- Ocupación del padre:

- Ocupación de la madre:

- Lugar de residencia (pueblo o ciudad donde vives con tu familia): 